\title{
Towards Improving Technical Performance of a 747 MW Thermal Power Plant
}

\author{
Muhammad Amir Raza ${ }^{1,}{ }^{*}$, Krishan Lal Khatri ${ }^{1}$, Sunila Akbar ${ }^{2}$, Muhammad Ibrar Ul Haque ${ }^{3}$ \\ ${ }^{1}$ Department of Electrical Engineering, NED University of Engineering \& Technology, Karachi, Pakistan \\ ${ }^{2}$ Department of Telecommunication Engineering, NED University of Engineering \& Technology Karachi, Pakistan \\ ${ }^{3}$ Department of Electrical Engineering, Sir Syed University of Engineering \& Technology, Karachi, Pakistan. \\ ${ }^{*}$ Corresponding author: amir.eed.neduet@gmail.com
}

Abstract

In this paper, performance evaluation and technical audit of a $747 \mathrm{MW}$ thermal power plant consisting of three generating units is conducted. The factors influencing the performance of the plant have been identified and improvements in processes and mechanical, electrical, instrumentation, and safety engineering are suggested. These improvements would result in better profitability, productivity, and performance. The paper further discusses technical issues and challenges and identifies key areas where improvements are possible. Future recommendation for the operation of the plant that would result in better throughput are also presented. The methodology of performance analysis presented in the paper will help improving operational efficiency of thermal power plants in developing countries.

Keywords-Technicality, Profitability, Efficiency, Performance, Technical Audit.

\section{Introduction}

$\mathrm{T}$ ECHNICAL audit is considered to be an effective technique or tool for the electrical and mechanical systems, where the real facts and figures are identified, studied thoroughly, and finally the facts with proper recommendations are highlighted [1]. When an organization commissions its new power plant for the process industry, the circumstances are relatively different. But as time passes, these circumstances are varied to a great extent [2]. At an initial level, best practices are followed to run the industry but with time these practices would become expensive and create a huge burden on the employer [3]. The technical audit is a useful technique for system perfection and gives the right suggestion at the right time for an instant issue which ultimately enhances the profitability of the organization [4]. Technical audit evaluates the complete system with a detailed emphasis on the equipment performance, their respective process, inventory, commercial and administrative activities along with each input to the system based on the experience [4]. Technical

ISSN: 2523-0379 (Online), ISSN: 1605-8607 (Print)

DOI: https://doi.org/10.52584/QRJ.1901.15

This is an open access article published by Quaid-e-Awam University of Engineering Science $\&$ Technology, Nawabshah, Pakistan under CC BY 4.0 International License. audit upgrades technicality, adds knowledge, increases productivity, enhances the quality of the working condition, develops skills and creates awareness among the technical staff [5]. The improvement facts are available everywhere just to identify the right facts where improvements are possible. The small improvements together make an efficient and effective system [5]. The technical audit technique is implemented to the whole system where past data and present data are gathered and compared with the observed data and solutions are provided to the system accordingly.

This technical audit approach is implemented on the 747 MW Combined Cycle Power Plant (CCPP). The 747 MW CCPP was installed by the Government of Pakistan at Guddu for meeting the future energy needs of the nation [6]. The site is located within the existing premises of the Guddu power complex in Sindh Province, Pakistan [7]. This power project comprises of two gas turbine units each of capacity 243 MW with two large boiler units including one steam turbine unit of capacity 261 MW [8]. The 747 MW CCPP was installed and commissioned by Harbin Power Engineering China (HPEC); whereas, Albario Engineering Pvt Ltd. (AEPL) was a strategic partner with HPEC for the electro-mechanical work [9]. The 


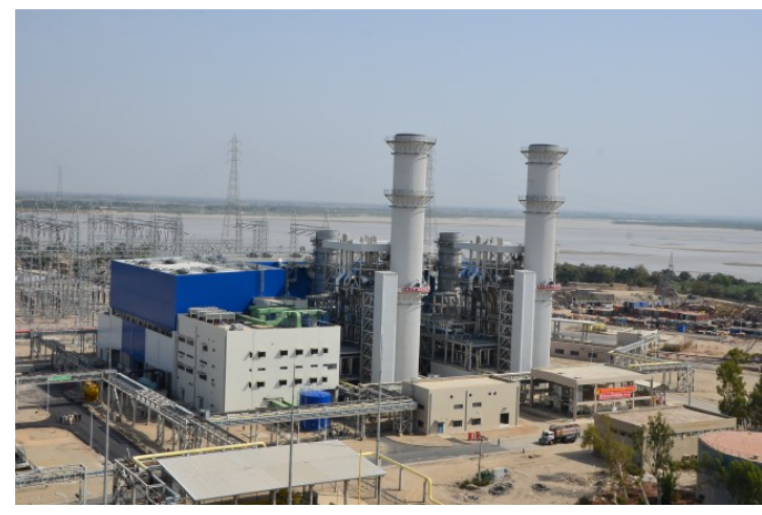

Fig. 1: 747 MW CCPP Guddu

747 MW CCPP is shown in Figure 1 [9]. This project has replaced existing power units 1 and 2 (installed in 1974) and units 3 and 4 (installed in 1980). These four units were completely derated, had spent their full lives, and were inefficient. Shutting down these units and transfering the supply of natural gas to the new 747 MW CCPP was beneficial [8]. The 747 MW CCPP is also suitable for high-speed diesel oil fuel. Now, this project is working with the configuration of $2+2+1$ means two gas turbine generators, two HRSGs, and one steam turbine generator under baseload conditions [10]. The modern 9FA Gas Turbine (9FA-GT) was installed because the efficiency of 9FA-GT is much greater than the conventional gas turbine and has a lesser generation cost/kWh [11]. The overall project cost was Rs 59775.41 million. The cost/KWh works out to be Rs. 80,000/- (equivalent to US\$ 964) [12]. The switchyard of $500 \mathrm{KV}$ has been installed in this 747 MW CCPP project which is supplying electricity to Guddu, Multan, and Muzaffargarh region [12].

\subsection{Objectives}

This audit seeks to satisfy the power generation organization to investigate whether the power station is being maintained in a manner that assures the security of supply, by assessing the station's compliance with the specific focus on the critical issues. As such audit involves the following.

1) The plant site is analyzed for its power capacity production and its fuel supply arrangement.

2) Discussion on the schematic arrangement of 747 MW CCPP.

3) Assessment of plant performance parameters including the operational capacity, plant outages, plant standby mode, plant availability factor, plant capacity factor, plant output factor, energy availability factor, heat rate, and efficiency of the system.
4) Identification of the major issues and challenges faced by 747 MW CCPP, which has large dominance on the plant performance parameters.

5) Carrying out a detailed technical audit to ensure the energy security of the system.

\subsection{Procedure}

Initially, a mock audit was performed by visiting the plant site. We gthered previous data and identified the basic challenges then a detailed technical audit was performed on the four areas which included plant site (process engineering), plant design (mechanical engineering), technical parameters (electrical engineering), and major issues about the managerial and safety.

\subsection{Scope}

The scope covers the four areas as discussed in the audit method section. In detail, following technical domains will be undertaken for this technical audit study: fuel supply arrangement, gas mixing station, compressor-turbine performance data, data for the combustion chamber, data for the filter house, heat recovery steam generator performance data, steam turbine and cooling tower performance data, performance data for the humidification pollution control equipments, performance data of pollution control equipments, consumption of lubricants, data for the major and repeated breakdowns, data for the tripping and identified its reasons, data for the transformer loading and oil data, data for the generator monitoring and safety data, review of maintenance practices, evaluation of control safety, training and development data, review the safety precautions and key features of emergency plant operation. We analyzed all the data categorically, identified the major reasons for the performance degradation, and recommended where improvement is possible.

\subsection{Limitations}

This technical audit has the following limitation.

1) The majority of the digital instruments were not calibrated for off/on measurements.

2) Unavailability of technical staff which creates problems for the instrument testing.

3) Testing of fuel for power generation is excluded.

4) Financial constraints including the pay-back period, internal rate of return, net present value, and life of the equipment were not part of this technical audit. 


\subsection{Significance}

Audit significance relates to the whole power system which is summarized as follows.

1) Determining the key issues and challenges for power system improvements.

2) Increasing power production using the proposed measures of this technical audit.

3) Cost benefits by improving system performance.

4) Helping in improving productivity and business.

5) Helping in reducing the environmental impacts.

6) Helping in improving customer satisfaction.

7) Helping in projecting a good image at the country level.

8) This study can be used as a baseline for other power systems in the developing countries.

\section{Literature Review}

There are three public sector power generation companies (GENCO's) in Pakistan which are managed by Pakistan Electric Power Company (PEPCO). The names of GENCO's are listed below [13];

1) Thermal Power Station (TPS) Jamshoro or Southern Power Generation Company Limited (SPGCL, GENCO-I).

2) TPS Guddu or Central Power Generation Company Limited (CPGCL, GENCO-II).

3) TPS Muzaffargarh or Northern Power Generation Company Limited (NPGCL, GENCO-III).

The major focus of this study is on TPS Guddu or (CPGCL, GENCO-II). The total installed capacity of TPS Guddu was 1655 MW [8]. The Government of Pakistan has established a new $747 \mathrm{MW}$ power station in Guddu in 2013. Currently, the total capacity is 2402 MW [8]. The unit wise complete description including unit capacity, commissioning year, fuel used, thermal efficiency, and the plant implementation country is given in Table 1 [14]. Chachar, Kandhkot, and Mari gas fields are responsible for supplying natural gas to TPS Guddu for the combustion process [14]. The calorific value of natural gas is normally low and medium which creates a low temperature and pressure at the combustion chamber and hence reduces the rotation per minute of the shaft. The efficiency of the gas turbine units is much greater than the steam units. The total number of employees of the powerhouse is around 1950 which are living in the residential colony built nearby to the plant. Other facilities include shopping centers, playgrounds, hospitals, mosques, schools, and recreational centers that are also provided to the employees in the premises of the residential colony. City Guddu has a large barrage available adjacent to the power plant. Normally, water is taken from Begari
Feeder (Guddu Barrage) for cooling towers and also for domestic use. For drinking purposes, water taken is first clarified and mineralized than supplied to the residential colony through large overhead tanks [15].

The location of the TPS Guddu plant is in the center of the country and has good connectivity with the national grid which supplies power to the major cities of Pakistan. The strong point of TPS Guddu is that it generates power on low and medium calorific value and can produce power on dual fuel combustion (natural gas and residential furnace oil). TPS Guddu is considered to be the swing customer for the gas utilities because it fulfills the residential and commercial needs throughout year [15]. TPS Guddu has a firm contract with gas utilities; whereas, TPS Jamshoro and TPS Muzaffargarh do not have a firm contract with the concerned gas industries. The contract status of GENCOS with gas utilities are shown in Table 2 [16]. Similarly, TPS Muzaffargarh has a contract with Pakistan State Oil (PSO) for supplying residual furnace oil; whereas, TPS Guddu and TPS Muzaffargarh do not have a firm contract with PSO [16]. Normally, PSO supplies furnace oil through tank Lorries, large wagons, and railway lines to respective GENCO only when there is demand for furnace oil. GENCO plants are designed at high kinematic viscosity of oil around 180 centistokes (cst) during summer and 120 cst during winter. The furnace oil storage capability of TPS Guddu is shown in Table 3 [15].

\section{Research Methodology}

The methodology adopted in this reserach aims too find the answers to the following questions.

- Is the research area suitable for the installation of a thermal power station?

- What is the schematic arrangement of $747 \mathrm{MW}$ CCPP?

- What are the essential factors considered in a technical audit study?

- What are the issues and challenges faced by 747 MW CCPP?

\subsection{Research Area}

The existing facilities at Guddu TPS include communication facilities, availability of potable water source, and convenient connectivity with national grid system have been selected for installation of $747 \mathrm{MW}$ CCPP due to Water and Power Development Authority (WAPDA's) ownership and infrastructure to ensure its economics [8]. The quantity of water required for condenser cooling is $42,000 \mathrm{~m}^{3}$ /hour. During cooling tower operation, the plant requires $1200 \mathrm{~m}^{3} /$ hour 


\begin{tabular}{|c|c|c|c|c|c|}
\hline Units nature & Units name & Commissioning Year & Fuel & Country of origin & Units capacity \\
\hline \multirow{4}{*}{ Steam Units } & Unit 1 & 1974 & Natural Gas & Czech Slovakia & $110 \mathrm{MW}$ \\
\hline & Unit 2 & 1974 & Natural Gas & Czech Slovakia & $110 \mathrm{MW}$ \\
\hline & Unit 3 & 1980 & Natural Gas/RFO & USSR & $210 \mathrm{MW}$ \\
\hline & Unit 4 & 1980 & Natural Gas/RFO & China & $210 \mathrm{MW}$ \\
\hline \multirow{9}{*}{ CCPP } & GT-7 & 1985 & Natural Gas & USA & $100 \mathrm{MW}$ \\
\hline & GT-8 & 1986 & Natural Gas & USA & $100 \mathrm{MW}$ \\
\hline & ST-5 & 1987 & $\mathrm{~N} / \mathrm{A}$ & USA & $100 \mathrm{MW}$ \\
\hline & GT-9 & 1986 & Natural Gas & USA & $100 \mathrm{MW}$ \\
\hline & GT-10 & 1986 & Natural Gas & USA & $100 \mathrm{MW}$ \\
\hline & ST-6 & 1988 & $\mathrm{~N} / \mathrm{A}$ & USA & $100 \mathrm{MW}$ \\
\hline & GT-11 & 1992 & Natural Gas & Germany & $136 \mathrm{MW}$ \\
\hline & GT-12 & 1992 & Natural Gas & Germany & $136 \mathrm{MW}$ \\
\hline & ST-13 & 1994 & $\mathrm{~N} / \mathrm{A}$ & Germany & $143 \mathrm{MW}$ \\
\hline \multirow{4}{*}{$\mathrm{CCPP}$} & & & & Total Capacity & $1655 \mathrm{MW}$ \\
\hline & GT-14 & 2013 & Natural Gas & China & $243 \mathrm{MW}$ \\
\hline & GT-15 & 2013 & Natural Gas & China & $243 \mathrm{MW}$ \\
\hline & ST-16 & 2013 & $\mathrm{~N} / \mathrm{A}$ & China & $261 \mathrm{MW}$ \\
\hline & & & & Total Capacity & $747 \mathrm{MW}$ \\
\hline
\end{tabular}

TABLE 1: Power units detail of TPS Guddu

\begin{tabular}{|l|l|l|}
\hline $\begin{array}{l}\text { Power } \\
\text { Station }\end{array}$ & Gas Supply Source & $\begin{array}{l}\text { Contract } \\
\text { Status }\end{array}$ \\
\hline \multirow{3}{*}{$\begin{array}{l}\text { TPS } \\
\text { Guddu }\end{array}$} & $\begin{array}{l}\text { Mari Gas - Mari } \\
\text { Gas Company }\end{array}$ & 60 MMscfd \\
\cline { 2 - 3 } & $\begin{array}{l}\text { Kandhkot Gas - Pakistan } \\
\text { Petroleum Limited }\end{array}$ & $\begin{array}{l}(110+90) \\
\text { MMscfd }\end{array}$ \\
\cline { 2 - 3 } & $\begin{array}{l}\text { Zamzama Gas - SNGPL } \\
\text { and SSGC Network }\end{array}$ & No contract \\
\hline $\begin{array}{l}\text { TPS } \\
\text { Jamshoro }\end{array}$ & $\begin{array}{l}\text { Sui Southern Gas } \\
\text { Company (SSGC) }\end{array}$ & No contract \\
\hline $\begin{array}{l}\text { TPS } \\
\text { Muzaffargarh }\end{array}$ & $\begin{array}{l}\text { Sui Northern Gas } \\
\text { Pipeline (SNGPL) }\end{array}$ & No contract \\
\hline
\end{tabular}

TABLE 2: Natural gas supply arrangement at TPS

\begin{tabular}{|l|l|l|}
\hline Power Station & $\begin{array}{l}\text { Furnace Oil } \\
\text { Tanks }\end{array}$ & $\begin{array}{l}\text { Storage } \\
\text { Capacity }\end{array}$ \\
\hline \multirow{3}{*}{ TPS Guddu } & 2 & 24,000 \\
\cline { 2 - 3 } & 4 & 21,000 \\
\cline { 2 - 3 } & 3 & 11,400 \\
\hline Total & 9 & 56,400 \\
\hline $\begin{array}{l}\text { TPS } \\
\text { Muzaffargarh }\end{array}$ & $\begin{array}{l}\text { Sui Northern Gas } \\
\text { Pipeline (SNGPL) }\end{array}$ & No contract \\
\hline
\end{tabular}

TABLE 3: RFO storage capacity of TPS Guddu

water for cooling towers as make up. The water is obtained from the B.S feeder canal, taking off from the Guddu barrage. However, during the canal closure period, water is drawn from the tube wells installed on the bank of the canal. The groundwater quality is good for use in plants [8].

\subsection{Schematic Arrangement of 747MW CCPP}

The schematic diagram of $747 \mathrm{MW}$ CCPP is shown in Figure 2. The full forms of the abbreviations in Figure 2 are as follows.

- G-1 $\rightarrow$ Gas Supply from Kandhkot gas field.
- G-2 $\rightarrow$ Gas Supply from Mari gas field.

- HRSG $\rightarrow$ Heat Recovery Steam Generator.

- G.S $\rightarrow$ Grid Station.

- Stepup T/F $\rightarrow$ Stepup Transformer.

- Aux: $\mathrm{T} / \mathrm{F} \rightarrow$ Auxiliary Transformer.

- EM $\rightarrow$ Energy Meter.

- $\mathrm{FM} \rightarrow$ Fuel Meter.

- NTDC $\rightarrow$ National Transmission and Dispatch Company.

\subsection{Essential Factors Considered in Technical Au- dit Study}

The key performance indicator for sustainable power supply include the plant operational capacity, plant outages, plant standby mode, plant availability factor, plant capacity factor, plant output factor, energy availability factor, heat rate, and efficiency of the system.

\subsubsection{Plant Operational Capacity}

Plant operational capacity usually refers to the maximum power production ability of the unit. It is termed as the maximum energy produced by the unit and used by the power distribution utilities. This operational capacity is taken into account when there is no equipment failure causing a reduction in the capacity and is considered that all the equipment and machinery are running at full load.

\subsubsection{Plant Outage Hours

$$
\text { Plant outage hours }=\mathrm{POH}+\mathrm{UOH}
$$

Planned outage hours (POH) is the sum of hours when the plant is manually shut down for routine maintenance activities and the annual overhauling whereas 


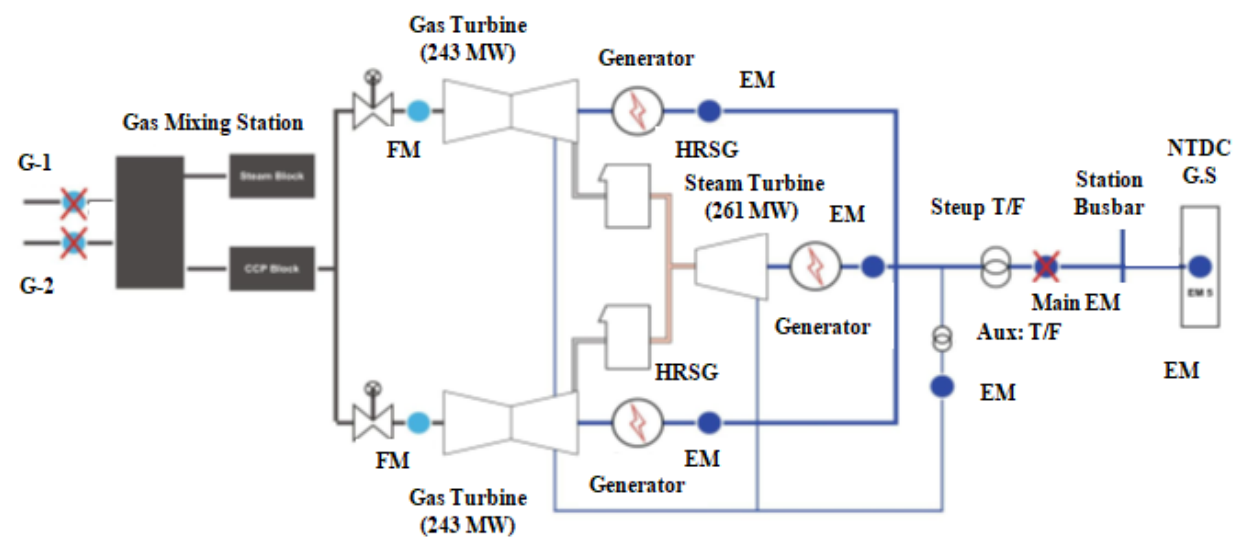

Fig. 2: Schematic diagram of 747 MW Combined Cycle Power Plant Guddu

Unplanned outages hours ( $\mathrm{UOH})$ is the sum of hours when the plant is offline due to any breakdown and equipment failure.

\subsubsection{Plant Standby Mode}

The standby mode of the power system refers to the system which is used for supplying the power during peak loads. All the power generators and transformers remain in the stationary condition and do not perform their primary functions. If a large power system remains at standby mode, it will operate during greater energy demand or in another case it will provide auxiliary power for any blackout or technical issue. However, in this study, there are other technical reasons for the standby mode plant.

\subsubsection{Plant Availability Factor}

The plant availability factor can be defined as follows,

$$
\text { Availability factor }=\frac{A H}{P H}
$$

where Availing Hours (AH) refer to the sum of plant shut down hours and plant service hours; whereas, Period Hours $(\mathrm{PH})$ refer to the sum of planned and unplanned outages hours. Furthermore, the equation of availability factor is modified due to the capacity lost because of poor load operation during a specified time.

Plant availability factor $=\sum$ (running hours

$\times$ poor load served + running hours $\times$ rated capacity $)$

$\times 100 \div($ total hours $\times$ rated capacity $)$

\subsubsection{Plant Capacity Factor}

The plant capacity factor can be defined as follows,

$$
\text { Plant capacity factor }=\frac{N G}{(N C \times P H)}
$$

where $N G$ is net generation, $N C$ is net capacity factor, and $P H$ is period hours. Capacity factor plays a crucial part in deciding how much electricity is produced from the available power capacity [17][18].

\subsubsection{Plant Output Factor}

The plant output factor can be defined as follows,

$$
\text { Plant output factor }=\frac{N G}{(N C \times S H)}
$$

where $N G$ is net generation, $N C$ is the net capacity, and $S H$ refers to service hours.

\subsubsection{Energy Availability Factor}

The net energy availability factor can be defined as follows,

$$
\text { Energy availaility }=\frac{(A H-P H-U H)}{T P H}
$$

where $A H$ is the available hours, $P H$ is the planned hours, $U H$ is the unplanned hours, and TPH is the total period hours.

\subsubsection{Gross and Net Plant Heat Rate}

The heat rate of a plant is the amount of thermal energy required to produce one unit of energy that is generally expressed in Kilocalories / Kilo watt-hours or Btu / Kilowatt-hours. Btu / Kilowatt-hours has been adopted as the standard units for heat rate in this study.

\subsubsection{Gross and Net Plant Efficiency}

The thermal efficiency of the power plant is also referred to as the efficiency of the plant which is the ratio of the output energy to the input energy of the plant. It is usually calculated as 3,412 / (heat rate of the plant), expressed in Btu units. Whereas, both gross and net 
efficiency could be gross or net depending on the point of measurement of the output of the plant. The gross efficiency is the ratio of the total energy generated from the plant to the total energy input. The net efficiency is calculated as the ratio of total energy sent out from the plant to the total energy input of the plant. The energy sent out is calculated by subtracting auxiliary consumption of the plant and losses of plant's cable and step-up transformer from the gross generation of the plant. In certain cases, a discrete sent out meter is installed at the plant that can provide a direct measure of the energy sent out from the plant.

\subsection{Technical Issues and Challenges Faced by Central Power Generation Company Limited}

There are several issues and challenges faced by 747 MW thermal power station as listed below.

1) There is no mechanism available for the measurement of furnace oil received from PSO as well as fed to the installed units from the storage facilities of the plant. The same applies to natural gas supplied and consumed at the power station. The gas supplied to the residential colony is not measured. Measurement instruments are either not calibrated, non-functional, or absent.

2) Power supply to the residential colony and auxiliary system was not measured appropriately resulted in a high loss of electricity.

3) None of the residual fuel oil samples complied with Pakistan Standard and Quality Control Authority (PSQCA) specifications.

4) Ash and water contents were also found to be higher than the maximum limits prescribed by the PSQCA.

5) There are no routine maintenance activities available on the site as a result of increasing heat rate and loss of output capability.

6) The overhauling process of the system is delayed because the national transmission and dispatch company (NTDC) refuses to shut downtime due to power shortage in the country and another reason is delaying in payments against the power sale.

7) The number of employees is working without any specialization and no training workshops are conducted by TPS Guddu for their employees.

8) Lack of monitoring evaluation system for whole the site as such massive oil spills and inappropriate combustion results in a higher rate of toxic emissions and effluent discharges causing environmental threats to the adjacent population.

\begin{tabular}{|c|c|c|c|}
\hline Units & Actual A.F & $\begin{array}{l}\text { As Per } \\
\text { PPA A.F }\end{array}$ & $\begin{array}{l}\text { Reduction } \\
\text { in A.F }\end{array}$ \\
\hline \multirow{3}{*}{$\begin{array}{l}\text { Gas Turbine } \\
\text { Unit } 1\end{array}$} & $80.4 \%$ & $82.6 \%$ & $2.2 \%$ \\
\hline & $82.4 \%$ & $82.6 \%$ & $0.2 \%$ \\
\hline & $61.9 \%$ & $82.6 \%$ & $20.7 \%$ \\
\hline Total & 9 & 56,400 & \\
\hline $\begin{array}{l}\text { TPS } \\
\text { Muzaffargarh }\end{array}$ & $\begin{array}{l}\text { Sui Northern } \\
\text { Gas Pipeline } \\
\text { (SNGPL) }\end{array}$ & No contract & \\
\hline
\end{tabular}

TABLE 4: Reduction in the availability factor (A.F) of different units

9) Lack of performance evaluation system as such no remedial measures taken for the betterment of the power system.

10) Lack of health and safety management system in the power station so there is a huge chance of risk for the system and employees.

\section{Results \& Discussion}

The following results are drawn from this study.

1) The operational capacity of unit number 2 of 747 MW CCPP remained lower (233.5 MW) than that of approved (241.72 MW) by National Electric Power Regulatory Authority (NEPRA). This resulted in an energy loss of around 63.105 million KWh, converting into a financial impact of 0.0271 billion rupees.

2) It has been observed that $747 \mathrm{MW}$ CCPP occupies greater outage hours than its specified limit mentioned in the power purchase agreement (PPA). As such, an energy loss of around 282.239 million KWh converting into a financial impact of 2.025 billion rupees.

3) It has been observed that both the units of 747 MW CCPP remained on standby mode for a longer duration because the supply of natural gas was limited from Chacher, Kandhkot, and Mari gas fields, leading to a financial loss to the national exchequer.

4) The plant availability factor of two gas turbines and one steam turbine unit is quite lower than the allowed limit as mentioned in PPA. The availability factor of these units are given in Table 4 .

5) The energy availability factor, output factor, and capacity factor of 747 MW CCPP remained as $59 \%, 79 \%$, and $75 \%$ respectively, which are quite low compared to those specified in the PPA. The unit wise energy availability factor, output factor, and capacity factor of $747 \mathrm{MW}$ CCPP are shown in Table 5. 


\begin{tabular}{|l|l|l|l|}
\hline Factors & Unit 1 & Unit 2 & Unit 3 \\
\hline Capacity factor & $67 \%$ & $69 \%$ & $43 \%$ \\
\hline Output factor & $83 \%$ & $83 \%$ & $69 \%$ \\
\hline Energy availability factor & $80 \%$ & $82 \%$ & $62 \%$ \\
\hline
\end{tabular}

TABLE 5: Energy availability factor, output factor, and capacity factor in percentage

6) Heat rate of power system were examined during winter season under the loading and operating condition. The values are a bit higher due to large variations noticed in the ambient condition. The gross and net heat rate and efficiency for the generation units are given in Table 6 .

7) Measurement systems for the energy generated, fuel received, and supplied to the combustion chamber were found to be inappropriate.

8) Due to the lack of technical staff, the key performance indicators are not getting any importance.

9) Limited financial resources are available for TPS Guddu for managing a large power complex.

\section{Conclusion}

Based on the technical interviews conducted with the plant officials, we analyzed the past and present performance aspects. Based on the actual observations during the technical audit, following conclusion is drawn from this study.

(a) Unit no 2 of 747 MW CCPP has shown $5 \%$ degradation in its operational capacity and hence affects the productivity of the plant.

(b) The plants have been using higher outage hours and remained on standby for a longer duration because of the unavailability of natural gas supply.

(c) The availability factor of the power station had dropped by $2.2 \%, 0.2 \%$, and $20.7 \%$ in units 1,2 , and 3 respectively. Unit 3 shows poor performance as compared to other two units.

(d) The net energy availability factor, output factor, and the capacity factor are found to be low which degrades the performance of the system.

(e) The efficiency is quite low as compared to the design efficiency. Hencce, it largely affects the profitability of the system.

The results in this technical audit study can be used for benchmarking purposes and preventive measures. This study can help the Government of Pakistan in making the system sustainable for future electricity supply.

\section{Recommendations}

The following recommendations are made for improving the performance of the 747 MW CCPP;
1) It is suggested to establish a research and development section for the technical problems and devise solutions accordingly.

2) Proper measurement and testing mechanism for the energy output and fuel quality may be established

3) Identifying and monitoring the key performance indicators on regular basis for better performance.

4) Facilitating the repair and maintenance activities to avoid the breakdown in the system.

5) Conducting training workshops for the employees and guiding them for the best industrial practices which are adopted by the international organizations.

\section{Acknowledgement}

The authors are highly thankful to the management of Central Power Generation Company (CPGCL) Guddu for permitting many technical visits for this study.

\section{References}

[1] S. Backlund and P. Thollander, "Impact after three years of the Swedish energy audit program", Energy, vol. 82, pp. 54-60, 2015.

[2] "Energy Management and Audit of Textile Mill", International Journal of Recent Trends in Engineering and Research, vol. 4, no. 3, pp. 66-71, 2018.

[3] J. Ho, S. Chou and T. Chandratilleke, "Energy audit of a steel mill", Energy, vol. 16, no. 7, pp. 1021-1029, 1991.

[4] S. V.J., "Energy Audit of an Organisation: A Case Study", Journal of Advanced Research in Dynamical and Control Systems, vol. 12, no. 4, pp. 1364-1369, 2020.

[5] R. Aparnathi and V. Dwivedi, "Scope of Energy Conservation and Energy Audit", International Journal of Electrical Energy, vol. 2, no. 3, 2014.

[6] NEPRA. "State of Industry Report (2013)", National Electric Power Regulatory Authority (NEPRA), Islamic Republic of Pakistan, 2013.

[7] NEPRA. "State of Industry Report (2014)", National Electric Power Regulatory Authority (NEPRA), Islamic Republic of Pakistan., 2014.

[8] The Express Tribune. "New 747MW power plant planned at Guddu.", 2012.

[9] Habib Rafiq (PVT.) LTD. "Project Name: 747 MW Guddu Power Plant.", 2014.

[10] NEPRA. "Indicative Generation Capacity Expansion Plan 2018-40", National Electric Power Regulatory Authority (NEPRA), Islamic Republic of Pakistan, 2019.

[11] M. Villanueva and J. Maglasang, "Computational and Experimental Study of a Gas/Steam Turbine - Derivative Axial Flow Impulse-Type Hydraulic Turbine", International Journal of Materials, Mechanics and Manufacturing, vol. 3, no. 2, pp. 86-91, 2015. Available: 10.7763/ijmmm.2015.v3.172.

[12] NTDC. "PAK: Pakistan Power Transmission Enhancement Program Tranche-IV (Dispersal of Power from 747 MW Power Plant at Guddu to Muzaffargarh)", Environment and Social Impact Cell (ESIC), NTDC for the Asian Development Bank. (2014), 2014. 
QUEST RESEARCH JOURNAL, VOL. 19, NO. 1, PP. 104-111, JAN-JUN, 2021

\begin{tabular}{|l|l|l|l|l|}
\hline Units & $\begin{array}{l}\text { Gross Heat Rate } \\
\text { (Btu/KWh) }\end{array}$ & Gross Efficiency (\%) & $\begin{array}{l}\text { Net Heat } \\
\text { Rate (Btu/KWh) }\end{array}$ & $\begin{array}{l}\text { Net Efficiency } \\
\text { (\%) }\end{array}$ \\
\hline $\begin{array}{l}\text { Gas Turbine } \\
\text { Unit 1 }\end{array}$ & 12,840 & 26.6 & 12,896 & 26.5 \\
\hline $\begin{array}{l}\text { Gas Turbine } \\
\text { Unit 2 }\end{array}$ & 13,412 & 25.4 & 13,467 & 25.3 \\
\hline $\begin{array}{l}\text { Steam Turbine } \\
\text { Unit 3 }\end{array}$ & - & - & - & - \\
\hline
\end{tabular}

TABLE 6: Gross and net heat rate and efficiency

[13] M. Baloch et al., "Hybrid energy sources status of Pakistan: An optimal technical proposal to solve the power crises issues", Energy Strategy Reviews, vol. 24, pp. 132$153,2019$.

[14] NEPRA. "Power System Statistics 2016-2017, 42nd Edition, Power System Planning (2017)", National Electric Power Regulatory Authority (NEPRA), Islamic Republic of Pakistan., 2017.

[15] ADB. Engconsult Ltd. for the Asian Development Bank., 2012.

[16] WB. "The Impact of the Global Financial Crisis on Investments in the Electric Power Sector: The Experience of India, Pakistan, and Bangladesh.", Energy Sector Management Assistance Program (ESMAP) and the World Bank., 2020.

[17] K. Khatri, M. Raza, S. Soomro, N. Tunio and M. Ali, "Investigation of possible solid waste power potential for distributed generation development to overcome the power crises of Karachi city", 2021.

[18] M. Raza, K. Khatri, K. Rafique and A. Saand, "Harnessing Electrical Power from Hybrid Biomass-Solid Waste Energy Resources for Microgrids in Underdeveloped and Developing Countries", Engineering, Technology \& Applied Science Research, vol. 11, no. 3, pp. 7257-7261, 2021. 